\title{
Compatible or Incompatible? DSI, Open Access and Benefit-sharing
}

\author{
Rodrigo Sara, Andrew Lee Hufton and Amber Hartman Scholz
}

\section{Introduction}

The scientific community has a strong tradition of sharing genetic sequence data, also known as Digital Sequence Information (DSI), in an unrestricted manner through public databases. This tradition of open access to DSI yields many non-monetary benefits including scientific reproducibility, research integrity, as well as the public good in fields such as biodiversity, ecology, public health and sustainable agriculture. Beyond non-monetary benefits, DSI can be used across the value chain directly or indirectly in bio-based commercialization.

This debate about DSI, currently a placeholder term, ${ }^{1}$ concerns data about deoxyribonucleic acid (DNA), ribonucleic acid (RNA) and protein sequences and potentially metabolites. ${ }^{2}$ The crux of the problem is that "the generation of [DSI] on genetic resources in most cases requires access to a [physical] genetic resource, although in some cases linking the [DSI] to the genetic resource from which it was generated may be difficult" 3 and "there is a divergence of views among Parties regarding benefit sharing from the use of [DSI] on genetic resources." 4 Some stakeholders consider open access itself to be a type of non-monetary benefit sharing because all nations are both using DSI and providing access to genetic resources (GR) used to generate DSI. ${ }^{5}$ Others view open access as a loophole that undermines fair and equitable

\footnotetext{
${ }^{1}$ Ad Hoc Technical Expert Group on Digital Sequence Information on Genetic Resources, Report of the Ad Hoc Technical Expert Group on Digital Sequence Information on Genetic Resources (2018) CBD/DSI/AHTEG/2018/1/4, [25] and Annex ([1]).

2 Open-Ended Working Group on the Post 2020 Global Biodiversity Framework, Digital Sequence Information on Genetic Resources (2021) CBD/WG2020/3/4, Annex II ([9] and Table 1).

${ }^{3}$ Conference of the Parties to the Convention on Biological Diversity, Report of the Conference of the Parties to the Convention on Biological Diversity on its Fourteenth Meeting (2019) CBD/COP/14/14, [258] and Annex (Decision 14/20, [4]).

4 Ibid., [258] and Annex (Decision 14/20, [6]).

${ }^{5}$ Amber Hartman Scholz, Matthias Lange, Pia Habekost et al., 'Myth-Busting the Provider-User Relationship for Digital Sequence Information' (2021) 10 GigaScience giab085; Matthias Lange, Blaise Alako, Guy Cochrane et al., 'Quantitative Monitoring of Nucleotide Sequence Data from Genetic Resources in Context of Their Citation in the Scientific Literature' (2021) 10 GigaScience giab084.
} 
benefit-sharing because DSI can be used without utilisation of the underlying genetic resource.

Tension has arisen in international discussions about access and benefit sharing (ABS) from genetic resources at the United Nations Environment Program's Convention on Biological Diversity $(\mathrm{CBD})^{6}$ and its Nagoya Protocol on Access to Genetic Resources and the Fair and Equitable Sharing of Benefits Arising from their Utilization to the Convention on Biological Diversity (Nagoya Protocol), ${ }^{7}$ the Food and Agriculture Organisation of the United Nation's International Treaty on Plant Genetic Resources for Food and Agriculture (ITPGRFA) ${ }^{8}$ and the World Health Organisation's Pandemic Influenza Preparedness Framework for the Sharing of Influenza Viruses and Access to Vaccines and Other Benefits (PIP Framework). ${ }^{9}$ In these discussions DSI is perceived by some Parties to create a "loophole" in these benefit-sharing agreements. Differences of opinion on the value of open access and its compatibility with benefit-sharing, underlie key points of divergence among the forums' participants. ${ }^{10}$

As these forums attempt to resolve the DSI disagreement, a number of researchers, research organizations, and nations have called for open access to be protected in any potential policy outcome that enhances benefit sharing. ${ }^{11}$ The scientific community in particular, has

\footnotetext{
6 (1992) 1760 U.N.T.S. 79 (CBD).

7 Conference of the Parties to the Convention on Biological Diversity, Report of the Tenth Meeting of the Conference of the Parties to the Convention on Biological Diversity (2010) UNEP/CBD/COP/10/27, [103] and Annex (Decision X/1, Annex 1, pp. 89-109) (Nagoya Protocol).
}

8 (2001) 2400 U.N.T.S. 303.

9 World Health Assembly, Sixty-fourth World Health Assembly (2011) WHA64/2011/REC/1, p. 8 (Resolution WHA64.5) and Annex 2 (Pandemic Influenza Preparedness: Sharing of Influenza Viruses and Access to Vaccines and Other Benefits).

10 See, for example, Lactitia Tshitwamulomoni and Gaute Voigt-Hanssen, 'Co-Leads' Summary of the Discussion of the Contact Group Regarding Areas of Potential Convergence and of Apparent Divergence on Digital Sequence Information on Genetic Resources' (2021) [10] available at <https://www.cbd.int/doc/c/a7d7/f5cf/c99a6073666521fafe5b320b/wg2020-03-cg-05-report-en.pdf> (15 December 2021).

${ }^{11}$ Calls for open access are evident in a number of the views submitted to the CBD pursuant to notifications requesting feedback, for example, Secretariat of the Convention on Biological Diversity, 'Notification 2021-063: Submission of Views and New Information on Policy Approaches, Options or Modalities for Digital Sequence Information on Genetic Resources' (2021) available at <https://www.cbd.int/conferences/post2020/submissions/2021-063> (15 December 2021); Secretariat of the 
cautioned that DSI is only usable if first compared to the global DSI dataset, that DSI's inherent value lies in its ability to be freely combined and shared, and suggested that only a solution that safeguards open access and these first two properties will be able to generate meaningful benefit sharing. ${ }^{12}$ Certainly, in other contexts, scientists and policy makers agree that open access is a clear goal of international research and innovation policy as evidenced for example, by a UNESCO Recommendation on Open Science adopted unanimously by its member countries in 2021. ${ }^{13}$ This broader trend towards open access and open science should be taken into account in any potential compromise or solution on the DSI issue.

The CBD Secretariat has introduced a set of benefit-sharing policy options to the international process for DSI (Figure 1). ${ }^{14}$ These options, however, are not granular enough to assess whether they are compatible with open access principles nor whether benefit-sharing is equally enabled across this spectrum. In this chapter, we explain what open access to DSI means in practice, assess the CBD Secretariat's DSI policy options through a more granular, technical lens, and discuss which policy options best enable open access and provide fair and equitable benefit-sharing. We show that de-coupled benefit sharing mechanisms for DSI are the most compatible with open access practices and, in general, multilateral mechanisms are the most suited for benefit sharing if fully de-coupled mechanisms become politically unrealistic.

Convention on Biological Diversity, '2019-2021 Inter-sessional Period: Submission of Views and New Information on Policy Approaches, Options or Modalities for Digital Sequence Information on Genetic Resources (OEWG3)' (2019) available at <https://www.cbd.int/dsi-gr/2019-2021/submissions> (15 December 2021). See also Amber Scholz, Upneet Hillebrand, Jens Freitag et al., Finding Compromise on ABS \& DSI in the CBD: Requirements \& Policy Ideas from a Scientific Perspective (Bundesministerium für Bildung und Forschung, 2020) p. 8 available at <https://www.dsmz.de/fileadmin/user_upload/Collection_allg/Final_WiLDSI_White_Paper_Oct7_2020.pdf> (15 December 2021).

12 Amber Hartman Scholz et al., "Multilateral benefit-sharing from digital sequence information will support both science and biodiversity conservation," Nature Communications (2022): https://doi.org/10.1038/s41467022-28594-0.

${ }^{13}$ United Nations Educational, Scientific and Cultural Organization, 'UNESCO Recommendation on Open Science' (UNESCO, 2021) p. 5 available at <https://en.unesco.org/science-sustainable-future/openscience/recommendation> (28 February 2022) (UNESCO Open Science Recommendation).

${ }^{14}$ Secretariat of the Convention on Biological Diversity (blog), 'Policy Options for Access and Benefit Sharing and Digital Sequence Information' (2021) available at <https://www.cbd.int/abs/DSIwebinar/DSIPolicyOptions2021.pdf> (15 December 2021). 


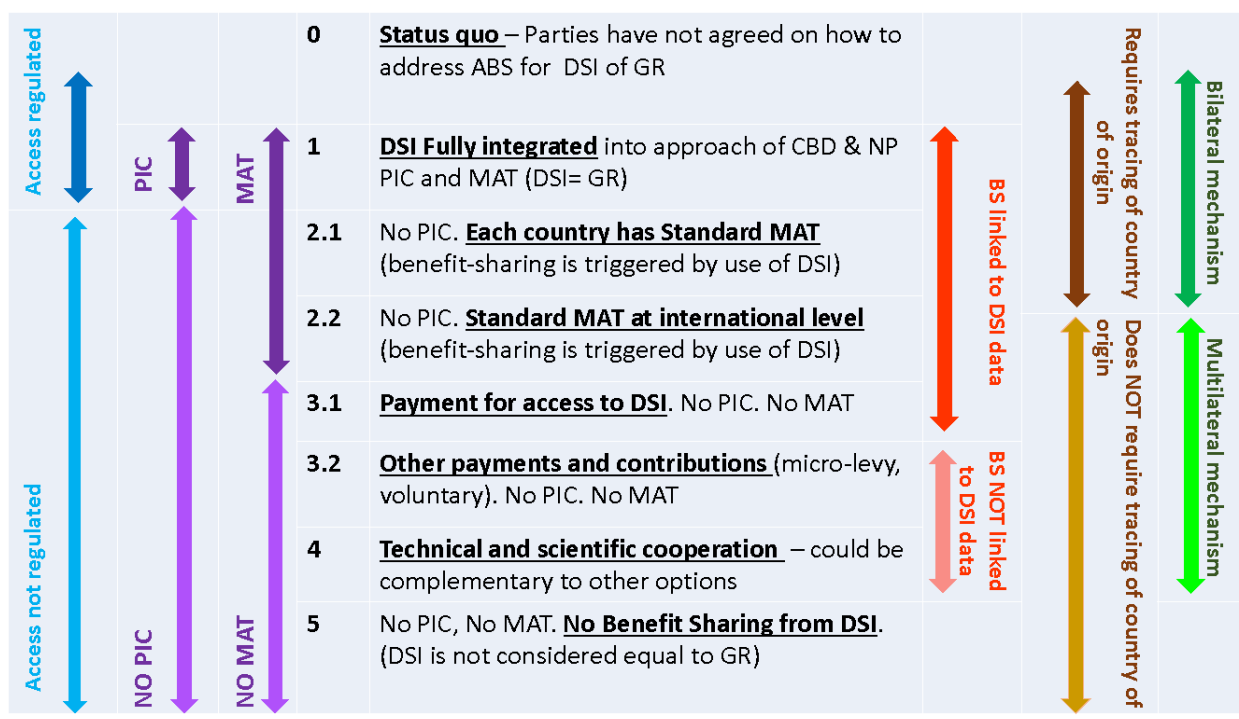

Figure 1: Summary of policy options identified by the Secretariat of the Convention on

Biological Diversity. ${ }^{15}$ Under the CBD and Nagoya Protocol (NP) facilitated access to genetic resources $(G R)$ required prior informed consent $(P I C)$ of the resource holder and mutually agreed terms (MAT) of access, including the benefits to be shared.

This chapter includes reflections by the authors following participation in a workshop on 'ABS for Utilization of DSI and Possible Consequences for Open Access' on 15-18 November 2021. ${ }^{16}$ It is informed by the authors' multidisciplinary experience in undertaking scientific research utilizing DSI and hands-on ABS experience, and shows that policy options that incorporate benefit sharing can, but need not, threaten open access to DSI.

\section{Why Open Access Matters?}

While the definition of 'open access' can vary depending on context, within the scientific domain it refers with consistency to regimes where outputs are accessible and reusable by anyone, either without restriction or subject to certain standard permissions governing reuse. The recently adopted UNESCO Open Science Recommendation provides a useful summary of the core principles that unite different open concepts in the context of scientific research,

\footnotetext{
${ }^{15}$ CBD/WG2020/3/4, above n. 7, Annex II (p. 14).

16 Organized by the German Federal Agency for Nature Conservation (BfN) at the International Academy for Nature Conservation on the Isle of Vilm. A meeting summary is available at <https://absch.cbd.int/en/database/VLR/ABSCH-VLR-SCBD-259978-2> (2021).
} 
including open data and open access to publications. ${ }^{17}$ In particular, it calls for scientific outputs to be 'as open as possible' subject to legitimate constraints in accordance with responsible data stewardship principles. ${ }^{18}$

Preserving open access to DSI is important for achieving the aims of the Global Biodiversity Framework ${ }^{19}$ and the Sustainable Development Goals, ${ }^{20}$ as well as for improving global public health, and for value creation in the commercial sector and other fields. ${ }^{21}$ Sequences, however, tend not to have value individually. A single sequence can only be fully understood once compared and integrated into the global dataset. The value of DSI grows from frictionless comparison, searching, processing, analyzing and linking of data and metadata across the entire dataset integrated into a vast database ecosystem. For instance, the mRNA vaccine technologies currently deployed to combat the spread of SARS-CoV-2 (the causative agent of COVID-19) were developed using our full knowledge of betacoronavirus and other viral sequences. One of Moderna's key patent filings relevant to their SARS-CoV-2 vaccine, for example, mentions hundreds of prior viral sequences from MERS-CoV, SARS-CoV and other viruses. ${ }^{22}$ Indeed, earlier work with MERS-CoV provided crucial knowledge on how to stabilize spike proteins, which has been used in both the Moderna and BioNTech vaccines. ${ }^{23}$ As a result, the final mRNA sequences used in both these vaccines are artificially modified using

\footnotetext{
17 UNESCO Open Science Recommendation, above n. 13, pp. 7-16.

18 Ibid., p. 11. The only restrictions considered justifiable are for the protection of human rights, national security, confidentiality, the right to privacy and respect for human subjects of study, legal process and public order, the protection of intellectual property rights, personal information, sacred and secret indigenous knowledge, and rare, threatened or endangered species' (p. 11).

19 See Conference of the Parties to the Convention on Biological Diversity, Kunming Declaration: 'Ecological Civilization: Building a Shared Future for All Life on Earth' (2021) CBD/COP/15/5/Add.1, [1].

20 United Nations General Assembly, Transforming our World: The 2030 Agenda for Sustainable Development (2015) A/RES/70/1.

21 Open access was expressly recognised in setting the Sustainable Development Goals through a Technology Facilitation Mechanism: ibid., [70].

22 Giuseppe Ciaramella and Sunny Himansu, 'Betacoronavirus mRNA Vaccine, United States US10702600B1' (2020) available at <https://patents.google.com/patent/US10702600B1/en> (15 December 2021).

23 Ryan Cross, 'The Tiny Tweak Behind COVID-19 Vaccines', Chemical \& Engineering News 29 September 2020 available at <https://cen.acs.org/pharmaceuticals/vaccines/tiny-tweak-behind-COVID-19/98/i38> (15 December 2021); Kizzmekia Corbett, Darin Edwards, Sarah Leist et al., 'SARS-CoV-2 MRNA Vaccine Design Enabled by Prototype Pathogen Preparedness' (2020) 586 Nature 567.
} 
this collective DSI knowledge, and do not correspond directly to any natural SARS-CoV-2 sequences.

\section{Characterizing Open Access to DSI in Public Databases}

DSI databases comprise a complex decentralized ecosystem of interdependent databases with 'upstream' and 'downstream' dimensions. Upstream, over 280 million high-quality genetic sequences are currently available through the synchronised databases of the International Nucleotide Database Collaboration (INSDC), ${ }^{24}$ which has a combined annual cost of approximately US\$50 million, borne predominantly by the governments of the United States, Japan and countries of the European Union. ${ }^{25}$ This provides the core infrastructure used by the global scientific community to efficiently store, share, analyse and link nucleotide sequence data and other data associated with genetic resources (e.g. transcriptomic, proteomic, epigenomic and metabolomic data) across a vast 'downstream' biological database ecosystem comprising over 2,600 public databases. ${ }^{26}$ There are no reliable estimates of the annual maintenance cost of these downstream databases. There is, however, consensus among database experts that the financial sustainability of this biological database ecosystem is a recurring challenge, ${ }^{27}$ which places at risk the continued maintenance of this vast data commons as an international public good. ${ }^{28}$

\footnotetext{
${ }^{24}$ For website see <https://www.insdc.org> (15 December 2021).

25 Ad Hoc Technical Expert Group on Digital Sequence Information on Genetic Resources, Digital Sequence Information on Genetic Resources: Concept, Scope and Current Use (2020) CBD/DSI/AHTEG/2020/1/4, [5] and Annex (p. 28).

${ }^{26}$ The $2019 / 20$ analysis of more than 2,600 public biological databases found that $99 \%$ of all biological databases that provide access to nucleotide sequence data were directly or indirectly dependent on the INSDC database infrastructure: ibid., Annex (p. 27).

27 W. Anderson, R. Apweiler, A. Bateman et al., 'Towards Coordinated International Support of Core Data Resources for the Life Sciences' (2017) bioRxiv 110825, pp. 4-5. See also Organisation for Economic Co-operation and Development, 'Business Models for Sustainable Research Data Repositories', OECD Science, Technology and Innovation Policy Papers No. 47 (2017) pp. 37-49 available at <https://www.oecdilibrary.org/docserver/302b12bb-

en.pdf?expires=1639552768\&id=id\&accname=guest\&checksum=407C9EBF7A08DA5ECF2D4B1AF357998C> (15 December 2021).

28 See Tom Dedeurwaerdere, Paolo Melindi-Ghidi and Arianna Broggiato, 'Global Scientific Research Commons under the Nagoya Protocol: Towards a Collaborative Economy Model for the Sharing of Basic Research Assets' (2016) 55 Environmental Science and Policy 1, 3-4.
} 


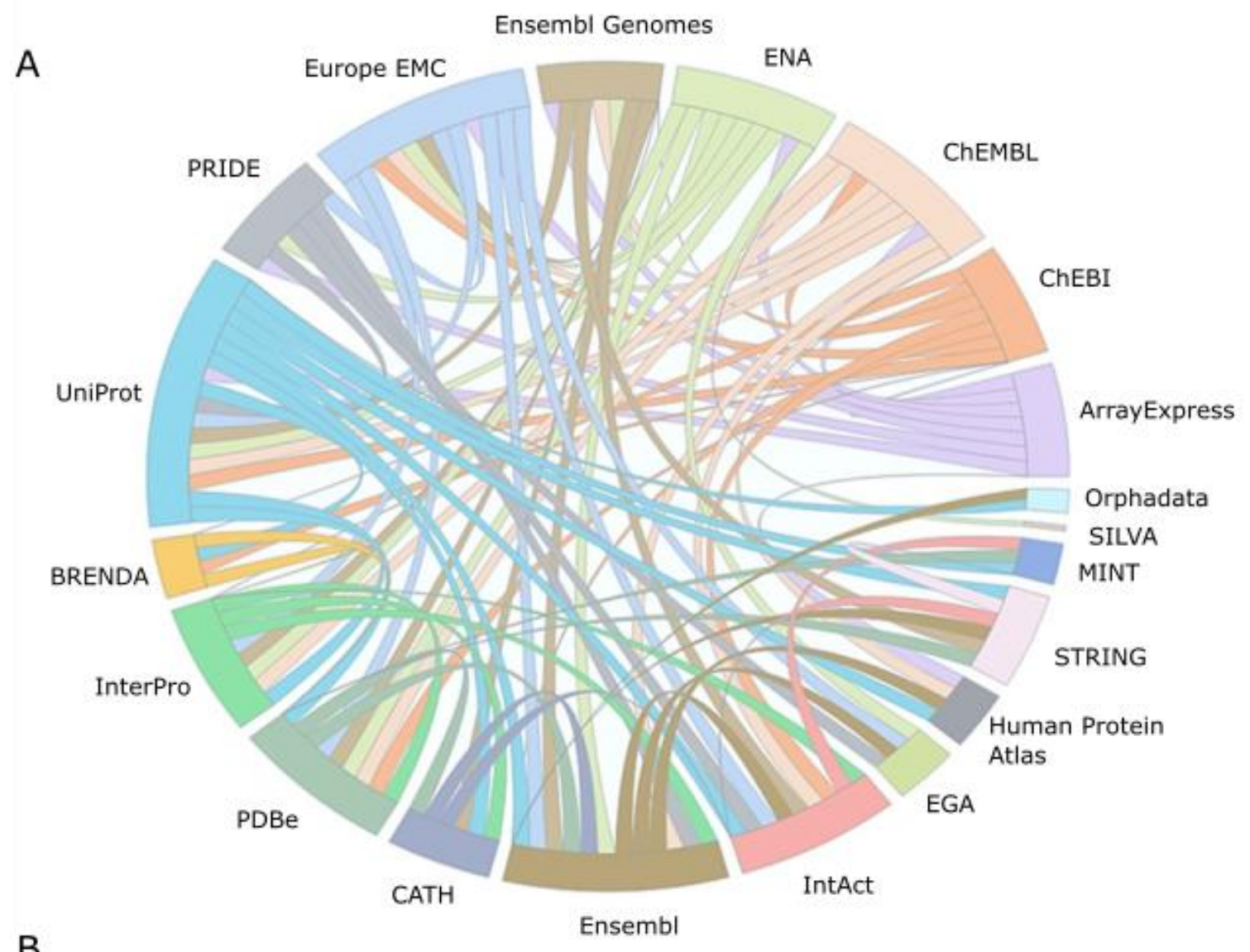

B

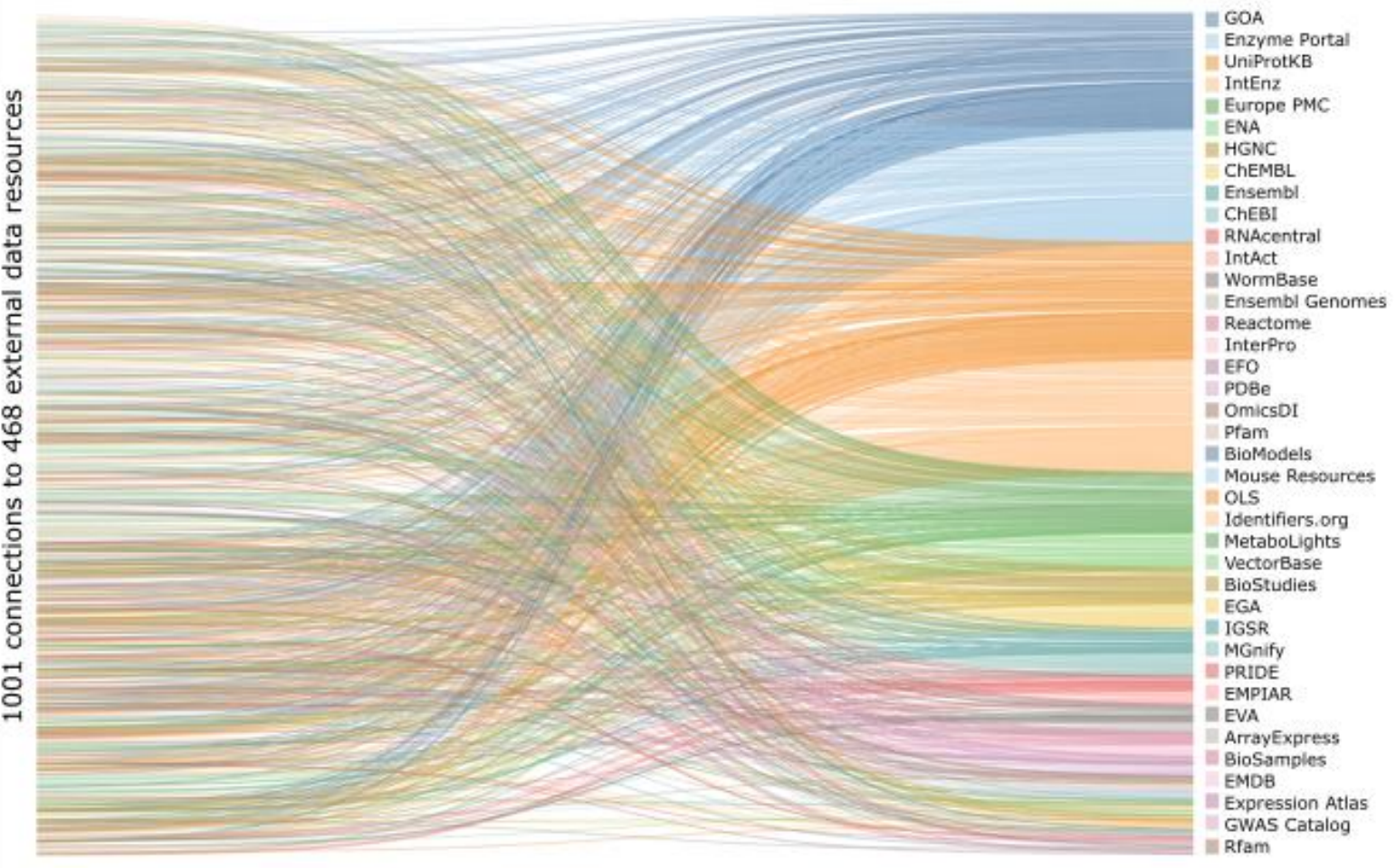

Figure 2. Biodata Resources: Open, Interconnected and Interdependent. (A) Data exchange 
among ELIXIR Core Data Resources; ${ }^{29}$ and (B) Data exchange between EMBL-EBI and external data resources ${ }^{30}$ (modified with permission from a presentation by Chuck Cook on behalf of the Global Biodata Coalition).

DSI is highly mobile and needs to be interconnected to be better understood and interpreted. For example, the data exchange among ELIXIR ${ }^{31}$ core resources and between the European Molecular Biology Laboratory-European Bioinformatics Institute (EMBL-EBI) ${ }^{32}$ data resources shown in Figure 2 provides a sense of some of the complexity of these large datasets and the resulting interconnectivity of these interconnected databases. Figure $2 \mathrm{~A}$ illustrates the interconnectivity between the different resources placed on the circumference of the circle with: (1) the size of the arc around the circle proportional to the total number of types of data directly exchanged; and (2) the width of the transects across the circle connecting different resources proportional to the number of links between the resources. ${ }^{33}$ Figure $2 \mathrm{~B}$ illustrates 1,001 known data connections between 39 EMBL-EBI resources and 468 separate external data resources. ${ }^{34}$ These illustrations shows the diversity and the high levels of connectivity between these resources. For example, in Figure 2A, BRENDA, an annotated enzyme database, receives data from a protein sequence and a chemical structure database and passes on its own dataset to two additional databases. These connections depend on the open and unhindered access to and exchange of data within and across databases. Disrupting open access to DSI in public databases through new restrictions or regulations intended to ensure benefit-sharing or even generate monetary benefits at every data intersection would

29 Rachel Drysdale et al., "The ELIXIR Core Data Resources: Fundamental Infrastructure for the Life Sciences," Bioinformatics 36, no. 8 (April 15, 2020): 2636-42, https://doi.org/10.1093/bioinformatics/btz959.

30 Charles E Cook et al., "The European Bioinformatics Institute in 2020: Building a Global Infrastructure of Interconnected Data Resources for the Life Sciences," Nucleic Acids Research 48, no. D1 (January 8, 2020): D1723, https://doi.org/10.1093/nar/gkz1033.

${ }^{31}$ ELIXIR is an EU-funded European research infrastructure that unites Europe's leading life science organisations in managing and safeguarding the increasing volume of data being generated by publicly funded research. See $<$ https://elixir-europe.org> (15 December 2021).

32 EMBL-EBI is the European Bioinformatics Institute, an Intergovernmental Organization which focuses on research and services in bioinformatics, as part of the European Molecular Biology Laboratory family. See <https://www.ebi.ac.uk> (15 December 2021).

33 Drysdale et al., "The ELIXIR Core Data Resources."

34 Cook et al., "The European Bioinformatics Institute in 2020." 
existentially challenge these connections potentially to their breaking point.. This would irreparably hinder research and innovation in the life sciences. This also has implications for science globally, given the extent to which open access - and related concepts such as open data and open science - feature prominently in science, innovation and economic policy at national and regional levels across the socio-economic spectrum. ${ }^{35}$ Even a carefully designed benefit-sharing solution for DSI could have unintended consequences if it disrupts open access to DSI in public databases, including exacerbating disparities in global scientific capacity.

The INSDC and other large biological data repositories typically provide access to DSI under terms that are unrestricted and well-aligned with concepts of "open access". ${ }^{36,37}$ Open access to DSI in these public databases can typically be characterized as follows: ${ }^{38}$

- Anonymous access: Most of the large DSI databases do not require a log-in to access data. This anonymity enables immediate use of the dataset and greatly simplifies automated use of the database via remote interfaces (computer-to-computer) transactions.

- Free of charge: Public DSI databases do not cost money to use. There are no financial barriers in place to use the data regardless of the purpose or outcome of the DSI use.

\footnotetext{
35 See, for example, United Nations Educational, Scientific and Cultural Organization, Towards a Global Consensus on Open Science: Report on UNESCO's Global Online Consultation on Open Science (UNESCO, 2020) p. 14 available at <https://en.unesco.org/science-sustainable-future/open-science/consultation> (15 December 2021).

${ }^{36}$ International Nucleotide Sequence Database Collaboration, 'International Nucleotide Sequence Database Collaboration Policy', available at <http://www.insdc.org/policy.html> (15 December 2021).

${ }^{37}$ Exceptions are noted in which DSI is shared in a manner that restricts access or use. These include, for example, controlled-access systems often used for human genetic data (e.g. the EGA, available at <https://egaarchive.org> (15 December 2021)), restricted terms of re-use (e.g. GISAID, available at <https://www.gisaid.org/registration/terms-of-use> (15 December 2021)), differentiated terms/licenses (e.g. GBIF, available at <https://www.gbif.org/terms> (15 December 2021)), and national ABS measures which either explicitly apply to access and use of DSI (see Ad Hoc Technical Expert Group on Digital Sequence Information on Genetic Resources, Fact-finding Study on How Domestic Measures Address Benefit-sharing Arising from Commercial and Non-commercial Use of Digital Sequence Information on Genetic Resources and Address the Use of Digital Sequence Information on Genetic Resources for Research and Development (2020) CBD/DSI/AHTEG/2020/1/5, Annex (pp. 11-18)).

${ }^{38}$ For an in depth evaluation of "open access" definitions and concepts in the context DSI, see this background report: Sara, Rodrigo et al., "Open Access: A Technical Assessment for the Debate on Benefit-Sharing and Digital Sequence Information" (Zenodo, January 14, 2022), https://doi.org/10.5281/ZENODO.5838273.
} 
- Free of restrictions: INSDC databases have terms of use that do not pass on any restrictions to their users. Smaller 'downstream' databases often take a similar approach or do not have explicit terms or licenses.

- Interoperable: This concept applies in both a technical and legal sense. As described above and in Figure 2, there is a frictionless flow of information across databases and applications that allows infinite re-uses of the DSI for any imaginable scientific purpose. The dataset is available for download and reuse to copy, analyse, re-process, pass to software, and so on, without distinction or discrimination as to purpose, user or country of origin.

- Transparency and reproducibility: The scientific community strongly encourages the attribution and recognition of previous scientific work and clear attribution to the work of others. However, there are no legal obligations to track and trace the use of DSI. Similarly, geographical or provenance information is important for the scientific record but legal implications of this information are scarce in the open access system.

These features of open access are critical to research and innovation involving DSI as they not only facilitate reproducibility of scientific research, but also drive scientific freedom and creativity. ${ }^{39}$ Accordingly, these features are the backbone that should be used to evaluate whether DSI policy options would significantly change or disrupt the status quo to open access in public databases. Disruption of some features may be tolerable whereas others may be less so; it is a question of trade-offs. For example, certain restrictions, if holistic and standardized, may be perceived as tolerable if they help protect other features of the open system, such as interoperability. Alternatively, some might view anonymous access as less important than free access. How different policy modalities would impact on these features of the open DSI ecosystem is addressed next.

\section{Translating Conceptual DSI Policy Options into Specific ABS Modalities}

The DSI policy options introduced by the CBD Secretariat in March 2021 (Figure 1) ${ }^{40}$ helped to facilitate a common understanding and to focus international deliberations, however, they

\footnotetext{
39 UNESCO Open Science Recommendation, above n. 13, pp. 7-16.

${ }^{40}$ CBD/WG2020/3/4, above n. 7, Annex II (p. 14).
} 
lack sufficient specificity to assess consequences for open access. This lack of clarity can cause misunderstandings about their implications even between experts. Some options could be implemented by multiple modalities increasing the confusion. Therefore, more nuanced modalities are necessary to facilitate side-by-side comparison. To evaluate the potential of DSI policy options to significantly change or disrupt the features characterizing open access, the authors developed and considered the following modalities, which were first characterised and evaluated in the workshop, ${ }^{41}$ and are described in Table 1: many licenses, standard open licenses, universal database terms, paywalls, premium fees and a micro-levy.

\begin{tabular}{|c|c|}
\hline \multicolumn{2}{|c|}{ CBD Options and ABS modalities for implementation } \\
\hline \multicolumn{2}{|c|}{ Option 0: Status Quo } \\
\hline \multicolumn{2}{|c|}{$\begin{array}{l}\text { Note: from an open access perspective this scenario is equivalent to 'many licenses' as countries will continue to } \\
\text { try regulating DSI utilization in their national laws, thus in different ways (Option 2.1) }\end{array}$} \\
\hline \multicolumn{2}{|c|}{ Option 1: DSI Fully integrated } \\
\hline \multicolumn{2}{|c|}{$\begin{array}{l}\text { Note: from an open access perspective this scenario is equivalent to 'many licenses' as DSI utilization would still be } \\
\text { regulated at the national level, thus in different ways (Option 2.1) }\end{array}$} \\
\hline \multicolumn{2}{|c|}{ Option 2.1: Each country has standard MAT } \\
\hline $\begin{array}{l}\text { Many } \\
\text { national } \\
\text { licenses }\end{array}$ & 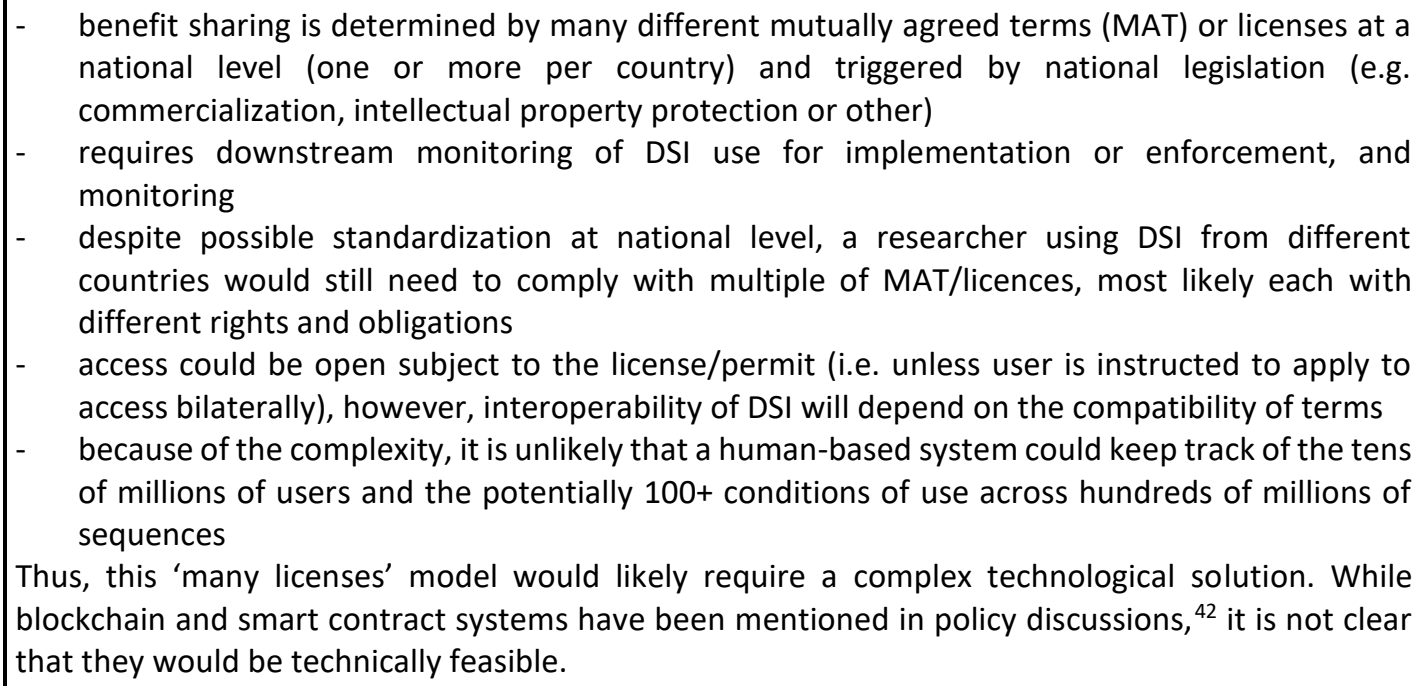 \\
\hline
\end{tabular}

\footnotetext{
41 'ABS for Utilization of DSI and Possible Consequences for Open Access' on 15-18 November 2021, above n. 16.

42 See, for example, Mark van der Waal, Carolina dos Ribeiro, Moses Ma et al., 'Blockchain-facilitated Sharing to Advance Outbreak R\&D' (2020) 368 Science 719.
} 
Option 2.2: Standard MAT at international level

\begin{tabular}{|c|c|}
\hline $\begin{array}{l}\text { Few open } \\
\text { licenses }\end{array}$ & 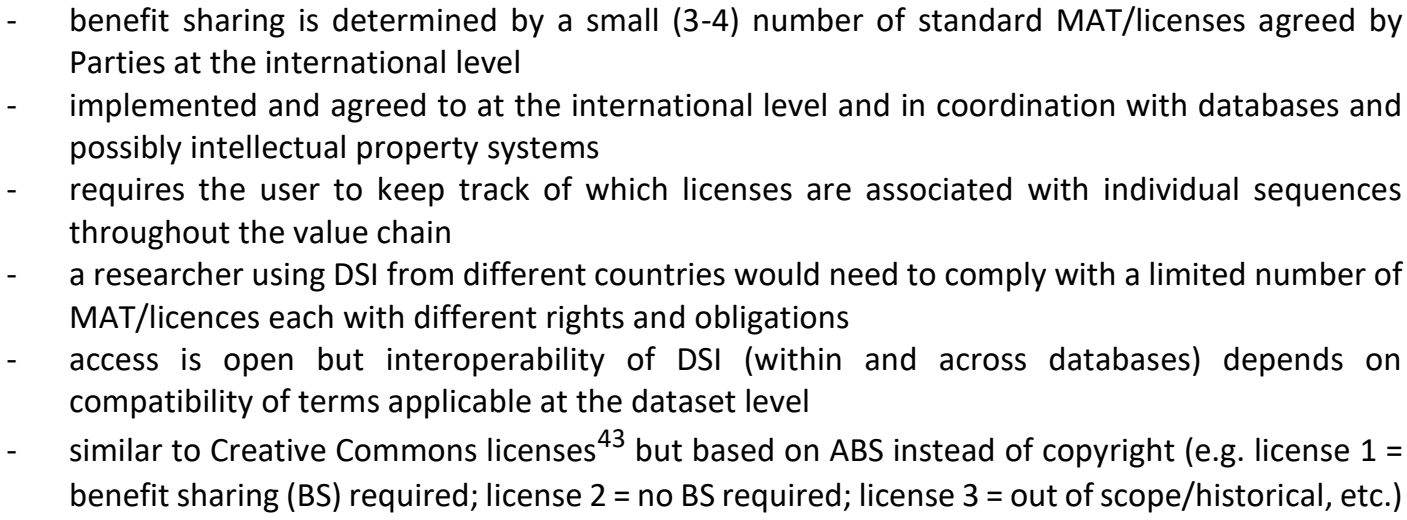 \\
\hline $\begin{array}{l}\text { Universal } \\
\text { database } \\
\text { terms }\end{array}$ & $\begin{array}{l}\text { - benefit sharing is determined by one standard MAT/licence agreed by Parties (e.g. similar to } \\
\text { the Standard Material Transfer Agreement in use for certain agriculturally-relevant plants) } \\
\text { and applied universally to DSI regardless of its country of origin or the treaty regime(s) which } \\
\text { governs its use } \\
\text { - } \text { implemented by uniform database terms of access and use across countries and treaties } \\
\text { - a researcher using DSI from different countries would need to comply with a uniform } \\
\text { MAT/licences (i.e. identical DSI rights and obligations across treaty fora) } \\
\text { - } \quad \text { access is open and interoperability of DSI is preserved } \\
\text { the user is directed by the standard MAT about their benefit sharing obligations }\end{array}$ \\
\hline
\end{tabular}

Option 3.1: Payment for access to DSI

\begin{tabular}{|l|ll|}
\hline Paywall(s) & $-\quad \begin{array}{l}\text { payment to DSI is coupled to access (i.e., access is not granted until payment is made) } \\
\text { fee can be determined following pre-negotiated criteria (e.g. flat rate per sequence or annual } \\
\text { fee; standard or differentiated on the basis of research application, sector of research, revenue; } \\
\text { etc.; fee exemptions or discounts are possible) } \\
\text { - } \\
\text { pay to see the data (comparing sequences, downloading sequences, and so on) } \\
\text { the DSI cannot connect to downstream databases because otherwise users would not pay the } \\
\text { fee (the business model depends on a closed system) } \\
\text { - A researcher using DSI from different countries would need to comply only with the paywall } \\
\text { fees, if applicable (i.e. no MAT/licences applicable (across treaty fora?) } \\
\text { access is closed (i.e. due to the paywall) and interoperability of DSI is only possible for those } \\
\text { databases that are behind the paywall }\end{array}$ \\
\hline Option 3.2: Other payments and contributions \\
\hline $\begin{array}{l}\text { Premium } \\
\text { fees }\end{array}$ & $\begin{array}{l}\text { no payment to access (comparing, downloading, and so on) sequences (i.e. de-coupled), } \\
\text { however, a premium (cloud-based) fee is payable to access value-added data, analysis and/or } \\
\text { services, or to 'unlock' certain permissions such as to use for a commercial purpose } \\
\text { dataset available in an open manner comparable to 'freeware' apps with additional power-user } \\
\text { features available for a fee (access to embargoed or value-added data; help desk; faster } \\
\text { download speeds or high-throughput analysis, etc.) }\end{array}$ \\
\hline
\end{tabular}

43 See <https://creativecommons.org> (15 December 2021).

44 See Secretariat of the International Treaty on Plant Genetic Resources for Food and Agriculture, 'The Multilateral System', available at <https://www.fao.org/plant-treaty/areas-of-work/the-multilateralsystem/the-smta/en> (15 December 2021). 


\begin{tabular}{|c|c|}
\hline & $\begin{array}{l}\text { - } \quad \text { a researcher using DSI from different countries could, for example, gain legal certainty if paying } \\
\text { the premium fees } \\
\text { - access is open for the 'freeware' component and closed for the 'premium' component and } \\
\text { interoperability of DSI (or a higher degree of interoperability) is preserved for premium users } \\
\text { - } \quad \text { fee can be determined following pre-negotiated criteria, as above }\end{array}$ \\
\hline Micro-levy & 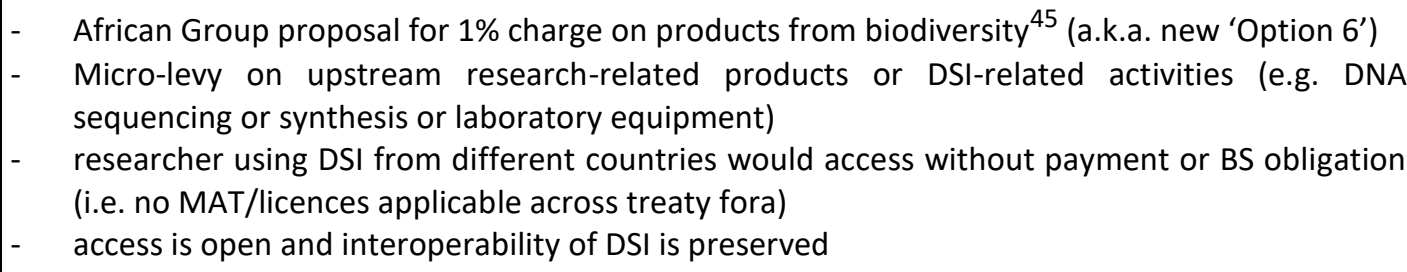 \\
\hline \multicolumn{2}{|c|}{ Option 4: Technical and scientific cooperation } \\
\hline \multicolumn{2}{|c|}{$\begin{array}{l}\text { Note: from an open access perspective this scenario has no impact on status quo and is likely to be combined with } \\
\text { one of the above options }\end{array}$} \\
\hline \multicolumn{2}{|c|}{ Option 5: No benefit sharing from PIC/MAT } \\
\hline
\end{tabular}

Table 1. Modalities derived from the CBD options. To enable technical analysis, policy options from Figure 1 were transformed into technical modalities (bold text in the left column). The same modality can be applied to multiple options (e.g. 0-2.1) or several modalities are possible within a single option (e.g. 2.2).

\section{Consequences for Open Access and Ranking of Modalities}

By evaluating each $A B S$ modality from the perspective of its potential to significantly change or disrupt the features that characterize open access to DSI in public databases, ${ }^{46}$ the overall compatibility of each modality with open access can be evaluated and the options can be ranked based on 'openness'. This is summarised in Table 2 below and includes observations regarding compatibility and other outstanding issues relevant for the design of the modality.

45 Open-Ended Working Group on the Post-2020 Global Biodiversity Framework, Report of the Open-Ended Working Group on the Post-2020 Global Biodiversity Framework on its Third Meeting (Part I) (2021), CBD/W2020/3/4., Annex III (p. 95) and Annex IV (p. 122). Noting that Namibia proposed the levy as part of a global multilateral benefit sharing mechanism ( $p .97$ ) with the composite text for DSI with bracketed language about the levy being subject to mutually agreed terms (MAT) and prior informed consent (PIC), so that it is unclear whether the levy proposal is in place of PIC and MAT and other bilateral arrangements for ABS (p. 95). 46 The workshop report provides a more comprehensive overview of the potential of each modality to significantly change or disrupt against the features which characterize open access to DSI in public databases: above n. 13. 


\begin{tabular}{|c|c|c|c|}
\hline & $\begin{array}{l}\text { Open } \\
\text { access }\end{array}$ & $\begin{array}{l}\text { Compatibility with current open } \\
\text { practice }\end{array}$ & Other issues \\
\hline $\begin{array}{l}\text { Many } \\
\text { licenses } \\
\text { (Option 0, 1, } \\
\text { or 2.1) }\end{array}$ & Low & $\begin{array}{l}\text { Customized licenses are generally } \\
\text { incompatible with open access } \\
\text { principles especially if the conditions } \\
\text { of those licenses prohibit open } \\
\text { sharing and redistribution. License } \\
\text { promulgation (many subsidiary } \\
\text { licenses) is also highly likely. }\end{array}$ & $\begin{array}{l}\text { The resulting legal uncertainty } \\
\text { could lead to mass avoidance (e.g. } \\
\text { filtering to exclude anything with a } \\
\text { license that is not open and } \\
\text { unrestricted). }\end{array}$ \\
\hline $\begin{array}{l}\text { Paywall } \\
\text { (Option 3.1) }\end{array}$ & Low & $\begin{array}{l}\text { 'Free of charge' is a key dimension of } \\
\text { open access that not only creates } \\
\text { equal global access but also enables } \\
\text { technical interoperability. Any } \\
\text { paywall is likely to be disruptive to } \\
\text { users and interconnected databases. }\end{array}$ & $\begin{array}{l}\text { Further clarity is needed regarding } \\
\text { how this approach would be } \\
\text { administered and in particular the } \\
\text { impact on interconnected } \\
\text { databases. }\end{array}$ \\
\hline $\begin{array}{l}\text { Standard } \\
\text { Open } \\
\text { Licenses } \\
\text { (Option 2.2) }\end{array}$ & Medium & $\begin{array}{l}\text { Open standard licenses are generally } \\
\text { compatible with open access } \\
\text { principles; however, differential } \\
\text { terms have the potential to } \\
\text { significantly disrupt interoperability } \\
\text { and frictionless flow of data where } \\
\text { license permissions or obligations } \\
\text { are inconsistent. }\end{array}$ & $\begin{array}{l}\text { Any differential requirements, } \\
\text { even simple ones like 'benefit } \\
\text { sharing required' or 'not required' } \\
\text { will also likely have undesirable } \\
\text { implications for avoidance and } \\
\text { easily facilitate jurisdiction } \\
\text { shopping. }\end{array}$ \\
\hline $\begin{array}{l}\text { Premium } \\
\text { fees (Option } \\
3.2 \text { ) }\end{array}$ & Medium & $\begin{array}{l}\text { 'Additional charges' (cloud-based } \\
\text { fees) may be less disruptive than a } \\
\text { paywall. Ultimately, it depends on } \\
\text { the extent to which 'freeware' } \\
\text { services preserve open access to DSI } \\
\text { in public databases. If additional } \\
\text { services are 'on top' of a free/open } \\
\text { access version of the public } \\
\text { databases, this modality may } \\
\text { provide more flexibility to address } \\
\text { the sharing of benefits resulting } \\
\text { from the use of DSI, in a nuanced } \\
\text { manner. }\end{array}$ & $\begin{array}{l}\text { Further clarity is needed as to how } \\
\text { this approach could be } \\
\text { administered and in particular the } \\
\text { impact on downstream databases. }\end{array}$ \\
\hline $\begin{array}{l}\text { Universal } \\
\text { database } \\
\text { terms } \\
\text { (Option 2.2) }\end{array}$ & High & $\begin{array}{l}\text { A change in database terms and } \\
\text { conditions if applied universally, } \\
\text { simply and with clear freedom to } \\
\text { operate will not disrupt other key } \\
\text { characteristics of open access in a } \\
\text { DSI context (i.e. no interoperability } \\
\text { issues, no discrimination). }\end{array}$ & $\begin{array}{l}\text { A 'one size fits all' could be difficult } \\
\text { to negotiate (i.e. in any single fora, } \\
\text { let alone multiple fora) and } \\
\text { consistent implementation could } \\
\text { be challenging across such a vast } \\
\text { database ecosystem globally. }\end{array}$ \\
\hline $\begin{array}{l}\text { Micro-levy } \\
\text { (Option } \quad 3.2 \\
\text { or } \quad \text { new } \\
\text { Option } 6^{47} \text { ) }\end{array}$ & High & $\begin{array}{l}\text { This is the best outcome from an } \\
\text { open access perspective. It is } \\
\text { unlikely to hinder research if } \\
\text { carefully designed and } \\
\text { implemented. }\end{array}$ & $\begin{array}{l}\text { A resource mobilization strategy } \\
\text { (i.e. to fund biodiversity } \\
\text { conservation and sustainable use } \\
\text { overall) dressed up as a DSI } \\
\text { solution may be difficult to } \\
\text { negotiate politically. It is unclear } \\
\text { how a global levy on consumers } \\
\text { would be implemented, who } \\
\text { would benefit (conservation or } \\
\text { economic development) and if }\end{array}$ \\
\hline
\end{tabular}

${ }^{47} \mathrm{Ibid}$ [42]. This modality and its origin is explained in Figure 1 above (see 'micro-levy' under Option 3.2). 
\begin{tabular}{|l|l|l|}
\hline & & $\begin{array}{l}\text { political will is sufficient to move } \\
\text { this option forward. }\end{array}$
\end{tabular}

Table 2. The compatibility of different DSI ABS modalities with open access.

From an open access perspective, a de-coupled multilateral modality such as a 'micro-levy' (i.e. Option 3.2) is the most compatible. A micro-levy is a small charge on a defined set of products intended to be small enough not to alter consumer behavior but carried by a wide consumer base such that significant financial proceeds are generated. See, for example, option 1 in the WiLDSI white paper. ${ }^{48} \mathrm{~A}$ micro-levy can be applied to a small set of products (e.g. molecular laboratory reagents) or to a broad swath of bio-based products as in the African proposal. ${ }^{49}$ Although many challenging questions related to its implementation immediately arise, it is the only option in which monetary benefits are completely decoupled from the use of DSI and database infrastructure (see Figure 1). It therefore presents the least change or disruption to the features that characterize open access. A de-coupled modality for DSI would necessitate that parties, in the exercise of their sovereign rights, would pursue benefit-sharing from DSI in a multilateral manner. This would, by extension, lead them also to widely forgo bilateral approaches to DSI benefit-sharing (although not necessarily for genetic resources). Put another way, DSI would be accessible and reusable by anyone but DSIbased commercial products would have an additional fee paid by the consumer. The details of how this micro-levy might be collected, the enforcement and compliance mechanisms, and how the proceeds of the levy might be distributed will need to be addressed further in future negotiations. Conversely, any bilateral modality involving many licenses will be the least compatible with open access as its implementation, which would need to be tightly coupled to DSI data and database infrastructure, represents the greatest disruption to the features which characterize open access.

\footnotetext{
${ }^{48}$ Amber Scholz, Upneet Hillebrand, Jens Freitag et al., Finding Compromise on ABS \& DSI in the CBD: Requirements \& Policy Ideas from a Scientific Perspective (Bundesministerium für Bildung und Forschung, 2020) p. 8 available at <https://www.dsmz.de/fileadmin/user_upload/Collection_allg/Final_WiLDSI_White_Paper_Oct7_2020.pdf> (15 December 2021)

${ }^{49}$ See section 6 alt. in CBD/SBI/3/CRP12 under <https://www.cbd.int/doc/c/0115/f139/a03cdb0ace728a1fc12eca40/sbi-03-crp-12-en.pdf>
} 
Beyond the option of a micro-levy, standard open licenses (Option 2.2), universal database terms (Option 2.2), and premium/cloud-based fees (Option 3.2) have the best potential to be compatible with open access but will depend on how these modalities are designed. Of these multilateral options, a paywall (Option 3.1) is expected to be the most disruptive to open access because it significantly compromises interoperability. The ability to iteratively process and re-distribute, re-analyze DSI for specific scientific communities and purposes would be fundamentally at risk as described above. Standard open licenses (Option 2.2) which, although generally compatible with open access, could also undermine interoperability because they create uneven operating conditions and legal uncertainty. Universal database terms (Option 2.2) overcome these interoperability issues and therefore seems a better fit for research and innovation. Premium/cloud-based fees (Option 3.2) are likely to be less disruptive to open access than a paywall given that some 'freeware' functionality will be retained and the approach allows for more fine-tuning or more nuanced design of the premium component that may help overcome deficiencies associated with other multilateral options. Although significant questions regarding its implementation and a lack of technical appreciation by policymakers may remain challenging.

\section{Conclusion}

Based on the current information available and the 40 -year plus practice of open access by DSI practitioners, the authors rank the current modalities for benefit sharing from DSI from 'least' to 'most' open as follows: many licenses (Option 1 and 2.1), paywall (Option 3.1), standard open licenses (Option 2.2), premium/cloud-based fees (Option 3.2), universal database terms (Option 2.2), and micro-levy (Option 3.2).

The above analysis has a narrow focus on the intersection of open access with DSI benefitsharing. However, parties will have additional criteria and aspects that they will also want to consider as they examine how they believe benefit-sharing from DSI can be pursued. Our focus on open access derives from our observation that many policymakers, although supportive in principle, of open access, remain unfamiliar with the technical requirements of open DSI. Thus, our analysis here is not an exhaustive analysis of relevant DSI evaluation 
criteria, but a specific lens intended to bring technical expertise to the DSI benefit-sharing discussion.

Despite these limitations, we believe there are several take-home messages that can inform the selection and design of an ABS modality for DSI. First, disrupting open access to DSI in public databases could have unintended consequences that are not yet perceived by the international community. So-called 'knock-on' effects of some modalities that, ironically, might widen the disparity in technological capacity that already exist globally. Open access is a powerful tool that helps to level the playing field and even seemingly 'techy' worries such as interoperability could have very dramatic effects on users across the globe that depend on access to niche downstream databases for their burgeoning research. Second, the costs incurred in maintaining access to DSI in public databases should not be taken for granted. They are significant and are usually internalized costs that should be accounted for on the balance sheet during the design of any benefit sharing part of a DSI solution.

Finally, the dilemma around DSI benefit-sharing could represent an opportunity to reexamine the entire ABS regime. The technical complexity of the DSI ecosystem makes a clear and compelling case for the need to simplify and standardise benefit sharing practices. Conceivably, this need for simplification and standardization is also overdue for genetic resources and perhaps this debate will allow for new overarching, global, standardized approaches to both genetic resources and DSI. 